\title{
Make4Change: Empowering Unemployed Youth through Digital Fabrication
}

\author{
Heidi Hartikainen \\ University of Oulu \\ Heidi.hartikainen@oulu.fi
}

\author{
Marta Cortés Orduña \\ University of Oulu \\ marta.cortes@oulu.fi
}

\author{
Marjukka Käsmä \\ University of Oulu \\ Marjukka.Kasma@oulu.fi
}

\author{
Iván Sánchez Milara \\ University of Oulu \\ ivan.sanchez@oulu.fi
}

\author{
Leena Ventä-Olkkonen \\ University of Oulu \\ Leena.Venta-Olkkonen@oulu.fi
}

\begin{abstract}
Recently, there has been a large body of research exploring the possibilities of digital fabrication and making in school context. To truly embrace the spirit of equity and democracy so essential to the maker movement, more research is needed concerning how these activities can be used to empower marginalized and at-risk groups. In this paper, we introduce preliminary insights from Make4Change project, that aims to strengthen the social inclusion and employability of unemployed, young people and immigrants outside the labor market through digital fabrication and making. We use the criteria for empowerment of participants as a tool to reflect the planning, organization, and execution of learning activities and on improving our process moving forward. We believe that insights from Make4Change will be useful to practitioners and researchers looking to empower underrepresented, marginal, or at-risk populations through making.
\end{abstract}

\section{CCS CONCEPTS}

- Human-centered Computing; • Human computer interaction (HCI); • Empirical studies in HCI;

\section{KEYWORDS}

Digital fabrication, Making, Empowerment, Unemployed, Marginalized

\section{ACM Reference Format:}

Heidi Hartikainen, Marta Cortés Orduña, Marjukka Käsmä, Iván Sánchez Milara, and Leena Ventä-Olkkonen. 2021. Make4Change: Empowering Unemployed Youth through Digital Fabrication. In FabLearn Europe / MakeEd 2021 - An International Conference on Computing, Design and Making in Education (FabLearn Europe / MakeEd 2021), June 02, 03, 2021, St. Gallen, Switzerland. ACM, New York, NY, USA, 5 pages.https://doi.org/10.1145/xxxxxxx.xxxxxxx

\footnotetext{
Permission to make digital or hard copies of all or part of this work for personal or classroom use is granted without fee provided that copies are not made or distributed for profit or commercial advantage and that copies bear this notice and the full citation on the first page. Copyrights for components of this work owned by others than the author(s) must be honored. Abstracting with credit is permitted. To copy otherwise, or republish, to post on servers or to redistribute to lists, requires prior specific permission and/or a fee. Request permissions from permissions@acm.org.

FabLearn Europe / MakeEd 2021, June 02, 03, 2021, St. Gallen, Switzerland

(c) 2021 Copyright held by the owner/author(s). Publication rights licensed to ACM. ACM ISBN $x x x-x-x x x x-x x x x-x /$

https://doi.org/10.1145/Xxxxxxx.Xxxxxxx
}

\section{INTRODUCTION}

Maker movement and digital fabrication aim to place cutting edge technology for design and small-scale fabrication on ordinary people's hands. This is expected to boost interest in STEAM and to support soft skills such as critical thinking, communication, collaboration [2,6]. However, some groups in our society are better equipped for a future full of digital technologies than others, causing a digital divide, i.e. polarization between those who have access and ability to develop skills related to them, and those who have not. Previous research in the area focuses heavily on the possibilities and challenges of integrating digital fabrication into the education of children (i.e. [3, 9-12, 14]), however there is also research advocating viewing making through the lens of culture and power in order to ensure equal opportunities for marginalized or disadvantaged groups [15]. Previous FabLearn papers have touched upon marginalized groups for example by exploring for example making meaningful making with refugees [5], and refugee children [8] and explored the possibilities of FabLabs with underprivileged young adults [13]. However, this kind of research is few and far apart. To truly embrace the spirit of equity and democracy of the maker movement, more research is needed on how digital fabrication can empower marginalized populations.

In this Work-in-Progress paper, we add to this body of knowledge, and present initial insights from the Make4Change project (later M4C), which aims to utilize digital fabrication and making to strengthen the social inclusion and employability of young people and immigrants currently outside the labor market. During the project, our goal is to develop a working model for how actors working with these groups can engage in digital fabrication to empower their participants, and to lower the threshold for them to use these processes independently. We present and discuss the activities carried out in M4C with one user group: unemployed youth between the ages 17-29 participating in Municipality Youth Workshops organized by the municipality (later MYWS). We use the criteria for the empowerment of participants [4] and a set of related questions [7] as a tool for reflecting on how we have planned and carried out activities with this group. We also discuss how to improve our process to better empower our target demographics through digital fabrication moving forward. We believe insights from M4C will be useful for practitioners and researchers working in FabLabs or makerspaces with underrepresented, marginal, or at-risk populations. 


\section{METHODOLOGY}

In this section, we present the structure of the M4C activities, the data collection and analysis process.

\subsection{Setting and Structure of Activities}

The purpose of the MYWS is to provide their customers (17-29 year old persons currently not working or studying) workshops on different topics to gain skills useful when seeking employment or further education. Duration and content of training is planned individually for each. So far we have collaborated with the Communication Workshop (later CWS) that engages participants in learning multimedia and graphical design, and arranged three activities for their participants: 1) Designing and fabricating (vinyl cutting) a logo for a peer 2) 3D modelling a Christmas ornament, 3) Designing and making a 3D object with laser cutter. Each activity took place in MYWS premises and lasted for ten hours (split in two sessions). Activity 1 was face-to-face. However due to COVID-19 pandemic, activity 2 was executed remotely, and activity 3 was implemented in hybrid sessions where we give instructions online from a room next to participants. Youth visit our room just to use the machines (e.g laser cutter). So far, M4C activities have had participants from 17 to early twenties, but we believe same activities can be organized for youngsters from 15 years old.

\subsection{Data Collection and Analysis}

The data analyzed in this paper was obtained from a collaborative workshop conducted between five researchers working in the M4C project. Pre-reading included the criteria on empowerment framework [4, 7]. During the 3-hour-workshop, we reflected on our experiences and goals, structuring our discussion with the help of reflective questions in the framework. The workshop was recorded, and one researcher wrote notes. The notes were shared between participants who had a chance to add their insights. Two researchers proceeded to organize the notes and formulate the content of the insights and discussion section under the framework of empowerment. Later, all proceeded to clarify and extend insights and discussion. This resulted in a structured set of reflections and ideas for future development described in following section.

\section{INSIGHTS AND DISCUSSION}

For our analysis, we use the Criteria for empowerment by Chawla and Heft [4] concerning how to enable children's effective and genuine participation in projects. The framework has been extended by Kinnula and Iivari [7] who developed a set of questions for those interested in empowering children through digital technology design. The questions are meant as a tool when planning and carrying out activities, and when evaluating and reflecting on them. The framework has been geared towards children, however we believe it is a useful tool also when working with unemployed youth. In this section, we present our insights on how conditions for empowerment realized in M4C activities and reflect on how we could improve in the future.

\subsection{Conditions of Convergence}

According to Conditions of Convergence, we should use aspects from youth's life as much as possible.
Are activities in line with organization curriculum? Is it easy and natural for youth to participate? Participants in the CWS had interest in media and ICT, and related skills (video production, 3D printing, photography) so integrating our activities into theirs was quite natural. In addition, the commitment of the workshop leader to the M4C activities further lowered barrier to participation. He was interested in planning and organizing activities with us to ensure they are beneficial for the youth.

Are existing structures supporting participation relied on? M4C activities have been organized at the premises of the MYWS, around their structures, routines, and schedules. In addition, we have utilized tools participants are acquainted with. Each has their assigned workstation. They installed necessary software before M4C activities, and we only had to bring needed machines (laser cutter, vinyl cutter)

Are activities based on youth's issues and interests? As participants might have learning difficulties, we decided to use a structured approach and scaffolded activities through guided tasks with clear goals. Participants could personalize designs, but the final product was defined (e.g. a logo for a bag, a candle holder). We did not give total freedom for participants as this often switches attention from learning the process towards the end results which can cause frustration if the final product is not what they expect.

What can we do when moving forward? We believe that enabling participants to see how digital designs can be turned into physical objects with examples, materials and tutorials provided by instructors will empower them to later work on individual projects in a more informed way. Learning needed skills together with others will help avoid frustration caused by misunderstanding limitations of the processes or own skills, and pave way for positive experiences and sense of accomplishment in future projects.

\subsection{Conditions of Entry}

According to Conditions of Entry, we should emphasize inclusive, voluntary, and accessible participation.

Have participants been selected fairly? Is participation voluntary? All youth in the CWS have been offered a chance to participate in M4C activities. While all have been encouraged to take part by the CWS leader, each may decide, whether to participate or not.

Is location and schedule for activities easy to access? The M4C activities have been integrated with the usual daily schedule of the workshop. When designing the activities, we considered the fact that each participant might be involved for a different period. Because of this, each activity was designed as a standalone piece of a bigger whole, each with the same basic structure.

What can we do when moving forward? The municipality organizes also other workshops in addition to the CWS, and we have contacted the leaders of those workshops to engage their participants in $\mathrm{M} 4 \mathrm{C}$ activities. However, it has proved difficult to get them involved for reasons such them not seeing how digital fabrication fits the focus of their workshop, or lack of adequate premises and equipment. From previous experience, we know leaders' lack of skills may cause a barrier for entry. In the future, we will focus on promoting our activities among workshop leaders, trying to provide feasible solutions to these concerns. 


\subsection{Conditions of Social Support}

To consider Conditions of Social Support, we should aim for a supportive and encouraging atmosphere. We believe that conditions of social support are especially important when arranging activities with unemployed youth. Firstly, unemployment can cause lower self-esteem and feeling of exclusion [1]. Secondly, some youth might have different kind of learning difficulties. In spite of our efforts, fostering practices that enable participants to support each other has proved challenging.

Do youth support and encourage each other? Is there team spirit? Do all act friendly and politely? Most M4C activities so far have focused on building individual skills, but because of time constraints and to learn group working skills, participants have also worked in pairs. We observed that all participants in are motivated and concentrate on their tasks. In the first f2f activity, we observed participants interacting with each other quite much. However, we perceived a change when we had to move instruction online: participants focused on individual tasks during the sessions, with minimal interaction with others. We are not sure if it was a real perception or a limitation in our observation (we had a single web-cam without two-way audio). The youth do not seem unfriendly or disrespectful but concentrated on their own matters. Perhaps they ignore others while they work, perhaps they respect each other's space. During these activities, we utilized online tools (e.g. Padlet) to promote anonymous group discussions.

Is the environment supportive? While we try to ensure everyone accomplishes the tasks set out and gain the skills specified for each session, we notice that participants rarely approach us for help without being prompted. Perhaps this is partly because not all had the chance to interact with us in the first session. As the pandemic has forced us to move the instruction online, we are perhaps seen as outsiders giving them tasks to accomplish, and only checking if everyone is done. Their leader is a clear authority figure for the participants who interacts with them more.

What can we do when moving forward? Most M4C activities so far have focused on building individual skills, but because of time constraints and to learn group working skills, participants have also worked in pairs. When the youth have mastered basic digital fabrication skills, we are planning to engage them in group projects where they will create products based on their own issues and interests that will be produced in bigger numbers and sold to the public. The goal of M4C is to engage the participants in societal discourse, and to improve their communication and team working skills to make sure all know their opinions and thoughts are valuable. We are currently researching best practices that will enable us to better scaffold social support and encouragement between participants during online activities.

\subsection{Conditions for Reflection}

To consider Conditions for Reflection, we should aim for transparency in our process and decisions.

Do power differences exist between participants? Who makes decisions? Researchers created initial plans and content for $\mathrm{M} 4 \mathrm{C}$ activities in collaboration with CWS leader. While researchers have a better understanding about the processes and technologies used, CWS leader has a deeper understanding of instructions and activities that are suitable for the youth. The researchers' role has been to introduce the processes, and guide the participants through design and making. The participants have worked independently on the tasks assigned. Until now the work has been structured and guided, but we will offer them the opportunity to design and work on their own projects, thus giving them more power in the process.

Are there occasions for reflection on the process and outcomes? Are there occasions for evaluation, on individual and group level? Youth have not been involved in planning $\mathrm{M} 4 \mathrm{C}$ activities, however they have been asked to give feedback about them (what can be improved) and reflect on their learning (e.g. how they could utilize new skills in the future, or which processes they would like to learn deeper). In the first activity, this was done through a group discussion. After instruction was moved online, youth have given feedback through anonymous online forms prepared to promote reflection. The reflection serves to: 1) to improve our activities and 2) to support youth to internalize and verbalize skills learned.

What can we do when moving forward? In general, obtaining reflection from the participants is challenging. To help the youth vocalize the skills they have acquired, we try to articulate them clearly at the beginning of each activity. There is still room for improvement to better encourage them to reflect and evaluate on our activities and their learning both on individual and group level. In the future, we will be looking into online tools that enable collaborative sharing and reflection during activities organically.

\subsection{Conditions for Competence}

Concerning Conditions for Competence, we should ensure youths competence increase during activities.

What kind of responsibility do youth have? The MYWS mimics a work-life experience and related responsibilities for participants. They all have contracts specifying the length and working hours. They are responsible for their conduct and they ensure break times and schedules are honored. Concerning M4C activities, they did not have any commitment, and they could leave our activity if they wished.

Who defines goals for activities? Are youth allowed to take part in defining the goals? Do all participants understand goals? So far, goals for M4C activities have been set by researchers together with the CWS leader, to ensure participants learn basic skills needed. The goals for the M4C activities have been made clear to youth during a starting presentation that outlines the activity and learning goals. Some participants with more technical skills have criticized not being able to come up with their own projects but have agreed to the limitations when the reasoning behind them has been made clear.

How much information do you provide at the beginning of the activities? Do youth have all information they need? How can they get it? All information needed for completing M4C activities has been provided in the beginning and throughout the process. Learning difficulties and other challenges have presented situations such as participants wishing to have more information at an earlier stage to make more informed choices, and others not being able to easily follow instructions. For this reason, we have provided instruction in different forms (verbally, visually, digitally 
and on paper) so participants may refer to them if necessary. Several instructors have been available in the online sessions to give guidance when necessary.

Does project result in tangible outcomes? Does learning build on previous knowledge/competences? Each M4C activity provided participants an opportunity to take home a tangible object once participants finish. The objects, as well as pictures and our observations, establish a set of artefacts which demonstrate the learning process. Learning has also been assessed through reflective discussions at the end of sessions. All activities build on previous knowledge and competences of participants and the target group is considered when setting the difficulty level and pre-requisites for tasks.

Does the work process support youth to initiate future projects by themselves? Due to the varying lengths of contracts the participants have at the CWS, there is lack of continuity in participation. Our goal is to attract participants to continue to work on their skillset in other M4C activities outside the workshop. In addition, during the activities we have supplied participants with information on where and how to find further guidance for creating future projects independently.

Do youth learn something? Do youth's activities have real impact? So far, youth have focused on individual projects on activities with clear goals to improve their skills related to digital fabrication such as 3D modelling, or 2D design and cutting. We have provided those that complete the tasks with learning badges (Open Badges) certified by the University that can be attached to their $\mathrm{CV}$ and help when they are applying for future jobs or continuing education.

What can we do when moving forward? In future $\mathrm{M} 4 \mathrm{C}$ activities, the participants will use acquired skills also in projects to benefit local charities. In addition to raising money for local charities these activities are designed to give our participants a stronger voice in societal discourse and thus have a positive impact on their social inclusion. In addition, we are currently devising more workshops based on feedback (for example connecting digital fabrication with business plan development) and drafting comprehensive project metrics to measure participant learning and overall project success. This will include for example follow-up interviews with participants six months after they finish with M4C activities, to follow up whether the skills they acquired sparked interest in further studies or helped them acquire a job or an internship.

\section{CONCLUSION}

In this paper, we used the framework of empowerment [4] and a set of related questions [7] to draw empirical insights from a set of educational activities we carried out with unemployed youth from MYWS. The framework allowed us to critically examine our work, and to focus when moving forward to better empower our participants through skills that support their study path and employability. Based on our insights we are encouraged for example to find new ways on how to promote social support between participants, to invite them to set their goals more clearly for activities, and to help them identify and reflect on competences they gain. Moving forward, we plan to include participants also from other organizations. The framework for empowerment will be used to plan, evaluate, and reflect on our work to maximize the impact of our activities and minimize potential pitfalls. Based on insights reported in this paper, we will build future activities upon three pillars: 1) Involving instructors in contact with the youth in preparation of the activities, to better take into account the weaknesses and strength of each group 2) Starting with a guided set of activities, and allowing participants take more agency after the foundation is set to ensure everyone gains basic skills needed and those valuable experiences of succeeding in individual projects later, and 3) Utilizing anonymous online communication tools to encourage reflecting and sharing ideas. Overall, we expect that empirical results from M4C will be useful for practitioners and researchers working in FabLabs with underrepresented, marginal, or at-risk populations, aiming to empower them through making.

\section{REFERENCES}

[1] Lars Axelsson and Göran Ejlertsson. 2002. Self-reported health, self-esteem and social support among young unemployed people: a population-based study. International Journal of Social Welfare 11, 2 (2002), 111-119. DOI:https://doi. org/10.1111/1468-2397.00205

[2] Tilde Bekker, Saskia Bakker, Iris Douma, Janneke van der Poel, and Koen Scheltenaar. 2015. Teaching children digital literacy through design-based learning with digital toolkits in schools. International Journal of Child-Computer Interaction 5, (September 2015), 29-38. DOI:https://doi.org/10.1016/j.ijcci.2015.12.001

[3] Fabio Campos and Tatiana Soster. 2018. What's a makerspace for? Investigating the integration of makerspaces into schools and communities. In Proceedings of the Conference on Creativity and Making in Education (FabLearn Europe'18), Association for Computing Machinery, New York, NY, USA, 106-107. DOI:https: //doi.org/10.1145/3213818.3213837

[4] Louise Chawla and Harry Heft. 2002. Children's Competence and the Ecology of Communities: A Functional Approach to the Evaluation of Participation. Journal of Environmental Psychology 22, 1 (March 2002), 201-216. DOI:https://doi.org/ 10.1006/jevp.2002.0244

[5] Nadine Dittert and Eva-Sophie Katterfeldt. 2018. Diversity in Digital Fabrication: Programming Personally Meaningful Textile Imprints. In Proceedings of the Conference on Creativity and Making in Education (FabLearn Europe'18), Association for Computing Machinery, New York, NY, USA, 112-113. DOI:https: //doi.org/10.1145/3213818.3219812

[6] Ole Sejer Iversen, Rachel Charlotte Smith, and Christian Dindler. 2018. From computational thinking to computational empowerment: a 21st century PD agenda. In Proceedings of the 15th Participatory Design Conference: Full Papers Volume 1 (PDC '18), Association for Computing Machinery, New York, NY, USA, 1-11. DOI:https://doi.org/10.1145/3210586.3210592

[7] Marianne Kinnula and Netta Iivari. 2019. Empowered to Make a Change: Guidelines for Empowering the Young Generation in and through Digital Technology Design. In Proceedings of the FabLearn Europe 2019 Conference (FabLearn Europe '19), Association for Computing Machinery, New York, NY, USA, 1-8. DOI:https://doi.org/10.1145/3335055.3335071

[8] Sarah Priscilla Lee and Marcelo Bonilla Worsley. 2019. Designing for and Facilitating Meaningful Making with Refugee Children. In Proceedings of FabLearn 2019 (FL2019), Association for Computing Machinery, New York, NY, USA, 89-95. DOI:https://doi.org/10.1145/3311890.3311902

[9] Iván Sánchez Milara, Kati Pitkänen, Jari Laru, Megumi Iwata, Marta Cortés Orduña, and Jukka Riekki. 2020. STEAM in Oulu: Scaffolding the development of a Community of Practice for local educators around STEAM and digital fabrication. International Journal of Child-Computer Interaction 26, (December 2020), 100197. DOI:https://doi.org/10.1016/j.ijcci.2020.100197

[10] Iván Sánchez Milara, Kati Pitkänen, Arto Niva, Megumi Iwata, Jari Laru, and Jukka Riekki. 2019. The STEAM path: building a Community of Practice for local schools around STEAM and Digital Fabrication. In Proceedings of the FabLearn Europe 2019 Conference (FabLearn Europe '19), Association for Computing Machinery, New York, NY, USA, 1-3. DOI:https://doi.org/10.1145/3335055.3335072

[11] Behnaz Norouzi, Marianne Kinnula, and Netta Iivari. 2021. Digital fabrication and making with children: Scrutinizing adult actor's strategies and challenges in mediating young people's activities. International Journal of Child-Computer Interaction (February 2021), 100267. DOI:https://doi.org/10.1016/j.ijcci.2021.100267

[12] Kati Pitkänen and Hanne Voldborg Andersen. 2018. Empowering Teachers and New Generations through Design Thinking and Digital Fabrication Learning Activities. In Proceedings of the Conference on Creativity and Making in Education (FabLearn Europe'18), Association for Computing Machinery, New York, NY, USA, 55-63. DOI:https://doi.org/10.1145/3213818.3213826 
[13] Emilia Louise Pucci and Ingrid Mulder. 2014. IK BEN STER(K): Empowering young adults through a peer-to-peer talent development platform. In Fablearn Europe 2018. Retrieved March 3, 2021 from http://fablearn.eu/2018/2014/05/21/ikben-sterk/

[14] Leena Ventä-Olkkonen, Heidi Hartikainen, Behnaz Norouzi, Netta Iivari, and Marianne Kinnula. 2019. A Literature Review of the Practice of Educating Children About Technology Making. In Human-Computer Interaction - INTERACT
2019 (Lecture Notes in Computer Science), Springer International Publishing, Cham, 418-441. DOI:https://doi.org/10.1007/978-3-030-29381-9_27

[15] Shirin Vossoughi, Paula K. Hooper, and Meg Escudé. 2016. Making through the Lens of Culture and Power: Toward Transformative Visions for Educational Equity. Harvard Educational Review 86, 2 (2016), 206-232. DOI:https://doi.org/ 10.17763/0017-8055.86.2.206 